\title{
Are Electronic Cigarettes Harmful? Mucin May Be the Key
}

\author{
Min-Seok Rha ${ }^{1}$ (D) $\cdot$ Chang-Hoon $\mathrm{Kim}^{1,2}$ (i) \\ ${ }^{1}$ Department of Otorhinolaryngology, Yonsei University College of Medicine, Seoul; ${ }^{2}$ The Airway Mucus Institute, Yonsei University \\ College of Medicine, Seoul, Korea
}

Electronic cigarettes (e-cigarettes) are devices that produce vapor by heating a liquid containing propylene glycol (PG), vegetable glycerin (VG), water, flavors, and nicotine [1]. E-cigarettes are presented as a healthier alternative to tobacco smoking, and thereby attract traditional smokers or non-smokers. In recent years, the use of e-cigarettes has increased dramatically among young people. However, the direct effects of e-cigarettes on health remain unclear, particularly on the respiratory system.

The airway epithelium acts as the first-line barrier against invading respiratory pathogens and noxious stimuli, and interacts with other immune cells to maintain homeostasis. The mucus layer covering the airway epithelium plays an essential role in host defense by removing pathogens via mucociliary clearance [2]. It is now evident that mucociliary dysfunction underlies several chronic respiratory diseases, such as chronic rhinosinusitis (CRS), asthma, chronic obstructive pulmonary disease, and cystic fibrosis [2].

In the current issue of Clinical and Experimental Otorhinolaryngology, Song et al. [3] investigated the effect of e-cigarette vapor on airway epithelial cells in the context of the expression of two major mucin proteins, MUC5AC and MUC5B. The authors reported that in vitro stimulation with e-cigarette vapor induced MUC5AC, but not MUC5B, upregulation in airway epithelial cells, including human pulmonary mucoepidermoid carcinoma cell lines and human primary nasal epithelial cells. Intriguingly, vapor-induced MUC5AC upregulation was observed regardless of the presence of nicotine stimulation, indicating that vapor alone exerts considerable effects on airway epithelial cells. Using inhibitors and siRNAs specific to each pathway, they also revealed that the ERK1/2, p38, and nuclear factor kappa-lightchain-enhancer of activated $B$ cells $(\mathrm{NF}-\kappa \mathrm{B})$ pathways are required for vapor-induced MUC5AC upregulation in airway epithelial cells.

Given that an increased mucin concentration and an altered
MUC5AC/MUC5B ratio are key pathologic features in smokers and patients with chronic airway diseases, MUC5AC upregulation in airway epithelial cells may be indicative of detrimental effects of e-cigarette use. A previous study also described that aerosolized PG and VG exposure increased intracellular levels of MUC5AC in human bronchial epithelial cells [4]. In line with this, proteomic analyses revealed that MUC5AC, but not MUC5B, expression was significantly higher in bronchial brush samples from e-cigarette users than in samples from non-smokers [4]. In addition, expression of immune-related genes was found to be decreased in nasal scrape samples from e-cigarette users [5], and MUC5AC expression was upregulated in mouse nasal epithelial cells following in vivo stimulation with PG and VG [4]. These findings suggest that e-cigarettes may induce impairment of the immune response in the upper airway mucosa. In this regard, future studies should address whether e-cigarettes aggravate chronic upper airway diseases, including CRS and allergic rhinitis. Furthermore, it would be of interest to delineate differences in vapor-induced changes between the upper airway and lower airway.

Although accumulating evidence suggests deleterious effects of e-cigarettes on respiratory health, the current understanding is still limited. Considering that decades-long tobacco smoking is needed for the development of chronic lung diseases, cohort studies with long-term follow-up of e-cigarette users are needed. In addition, more in-depth investigations using in vitro and animal models would provide mechanistic insights into e-cigaretteinduced changes in the airway epithelium.

\section{CONFLICT OF INTEREST}

No potential conflict of interest relevant to this article was reported.

Copyright (C) 2021 by Korean Society of Otorhinolaryngology-Head and Neck Surgery.

This is an open-access article distributed under the terms of the Creative Commons Attribution Non-Commercial License (https://creativecommons.org/licenses/by-nc/4.0)

which permits unrestricted non-commercial use, distribution, and reproduction in any medium, provided the original work is properly cited. 


\section{ORCID}

Min-Seok Rha https://orcid.org/0000-0003-1426-7534

Chang-Hoon Kim https://orcid.org/0000-0003-1238-6396

\section{AUTHOR CONTRIBUTIONS}

Conceptualization: all authors. Data curation: all authors. Formal analysis: all authors. Writing-original draft: MSR. Writingreview \& editing: $\mathrm{CHK}$.

\section{REFERENCES}

1. Dinakar C, O'Connor GT.The health effects of electronic cigarettes. N Engl J Med. 2016 Oct;375(14):1372-81.

2. Fahy JV, Dickey BF. Airway mucus function and dysfunction. N Engl J Med. 2010 Dec;363(23):2233-47.

3. Song SY, Na HG, Kwak SY, Choi YS, Bae CH, Kim YD. Changes in mucin production in human airway epithelial cells after exposure to electronic cigarette vapor with or without nicotine. Clin Exp Otorhinolaryngol. 2021 Aug;14(3):303-11.

4. Ghosh A, Coakley RC, Mascenik T, Rowell TR, Davis ES, Rogers K, et al. Chronic e-cigarette exposure alters the human bronchial epithelial proteome.Am J Respir Crit Care Med. 2018 Jul;198(1):67-76.

5. Martin EM, Clapp PW, Rebuli ME, Pawlak EA, Glista-Baker E, Benowitz NL, et al. E-cigarette use results in suppression of immune and inflammatory-response genes in nasal epithelial cells similar to cigarette smoke. Am J Physiol Lung Cell Mol Physiol. 2016 Jul;311(1): L135-44. 